\title{
HEMODILUTION AND WHOLE BODY OXYGEN BALANCE DURING NORMOTHERMIC CARDIOPULMONARY BYPASS IN DOGS
}

Beng-Ling Liam, MB, BS, MMed (Anaesthesia)

Walter Plöchl, MD

David J. Cook, MD

Thomas A. Orszulak, MD

Richard C. Daly, MD
Objective: The purpose of this study was to determine the minimum hematocrit value that can support whole body oxygen consumption during normothermic cardiopulmonary bypass. The effect of hemodilution on peripheral resistance, whole body oxygen delivery, and oxygen consumption was determined over a range of hematocrit values. Methods: Measurements were obtained during $38^{\circ} \mathrm{C}$ cardiopulmonary bypass with progressive normovolemic hemodilution (hematocrit value $40 \%$ to $9 \%$ ) in nine dogs. Dextran $70(6 \%)$ was used as a diluent. Anesthesia consisted of high-dose fentanyl and midazolam. A mean arterial pressure of $60 \mathrm{~mm} \mathrm{Hg}$ was maintained throughout cardiopulmonary bypass via increases in pump flow. Results: Progressive hemodilution was associated with a decreasing total peripheral resistance. During normothermic cardiopulmonary bypass with a whole blood prime, the whole body oxygen consumption approximated values previously reported in dogs under nonbypass conditions. Oxygen delivery and whole body oxygen uptake were maintained between a hematocrit value of $39 \%$ and $25 \%$. Significant decreases for both were seen when the hematocrit value was reduced to $18 \%$ and below. Conclusions: A hematocrit level greater than $18 \%$ was needed to maintain systemic oxygen delivery and consumption during warm cardiopulmonary bypass. The critical hematocrit value may be higher under bypass than nonbypass conditions because the flow increases that are practical during cardiopulmonary bypass do not approximate those seen in response to hemodilution of the intact circulation. Finally, the critical hematocrit value for the body may be higher than that required for the brain during warm cardiopulmonary bypass. (J Thorac Cardiovasc Surg 1998;115:1203-8)
A lthough hemodilution is standard practice during cardiopulmonary bypass (CPB), the limits of hemodilution at differing extracorporeal temperatures have not yet been systematically determined. ${ }^{1}$ The purpose of this study was to define the minimal hematocrit value that supports whole body oxygen consumption during normothermic CPB.

From the Department of Anesthesiology and the Division of Cardiovascular and Thoracic Surgery, Department of Surgery, Mayo Clinic, Rochester, Minn.

Supported in part by the American Heart Association-Minnesota Affiliate and the Mayo Foundation.

Received for publication August 15, 1997; revisions requested Nov. 17, 1997; revisions received Dec. 17, 1997; accepted for publication Dec. 22, 1997.

Address for reprints: David J. Cook, MD, Department of Anesthesiology, Mayo Clinic, 200 First St. SW, Rochester, MN 55905.

Copyright (C) 1998 by Mosby, Inc.

$0022-5223 / 98 \$ 5.00+0 \quad \mathbf{1 2} / \mathbf{1} / \mathbf{8 8 6 9 1}$
The systemic response to hemodilution under non-CPB conditions is well described. Under normal conditions, systemic and regional oxygen consumption is independent of oxygen delivery. Oxygen delivery and consumption are maintained during moderate hemodilution by increases in cardiac output, increases in tissue blood flow, and later by an increase in tissue oxygen extraction. ${ }^{2-4}$ However, for the individual organ and the body as a whole, there is a critical hematocrit value at which oxygen consumption becomes delivery-dependent. In the dog, under non-CPB conditions, systemic oxygen consumption is maintained to a hematocrit value of approximately $10 \% .^{5}$ The same physiology is applicable during $\mathrm{CPB}$, during which whole body oxygen balance is actively manipulated by changes in hematocrit value, temperature, and pump flow.

Transfusion practice varies greatly in cardiac surgery and improved transfusion guidelines are needed. ${ }^{6,7}$ These issues are made more pressing 


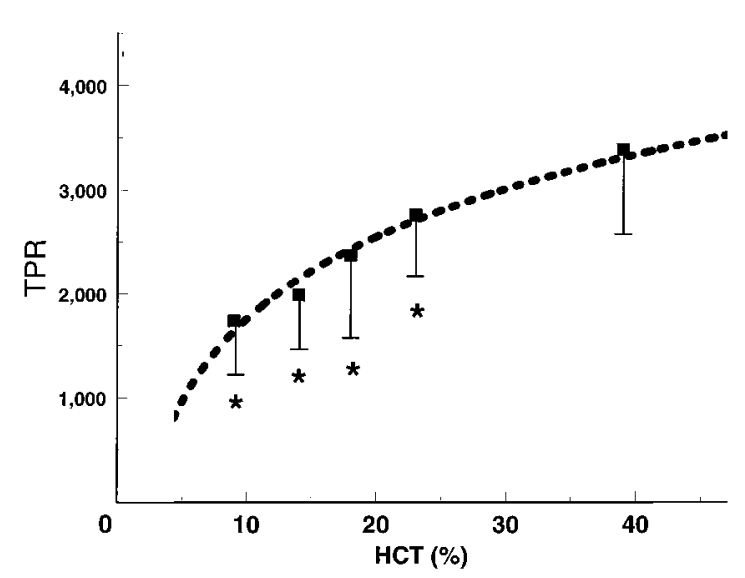

Fig. 1. Total peripheral resistance (TPR) in dynes • $\mathrm{sec} \cdot \mathrm{cm}^{-5}$ versus hematocrit $(\mathrm{Hct})$ during the five CPB study periods. Values are mean \pm standard deviation $(n=$ 9). A regression curve was generated from 45 individual values of TPR at individual hematocrit values.

with the shift to normothermic CPB in the past few years. ${ }^{8,9}$ Given the higher oxygen demand associated with "warm" $\mathrm{CPB},{ }^{10}$ there is a tendency to transfuse more frequently, but this practice is not based on a systematic evaluation of hemoglobin requirements. In fact, variability in transfusion practice arises in part because the relationship between temperature, hematocrit level, and oxygen balance has not been adequately characterized.

In evaluating the relationships between hematocrit value, systemic oxygen consumption, and oxygen delivery during normothermic $\mathrm{CPB}$, we hope to provide a more physiologic foundation on which to make decisions on perfusion and hematocrit management during $\mathrm{CPB}$.

\section{Materials and methods}

After review and approval by the Institutional Animal Care and Use Committee of the Mayo Clinic, nine unmedicated fasting adult mongrel dogs weighing 17 to 20 $\mathrm{kg}$ were studied. The dogs were placed in an acrylic plastic box (Plexiglas box, Rohm and Haas Company, Philadelphia, Pa.) and anesthesia was induced with halothane $3 \%$ to $4 \%$ inspired. After the onset of anesthesia, peripheral intravenous access was secured, muscle relaxation was obtained with pancuronium $\left(0.1 \mathrm{mg} \cdot \mathrm{kg}^{-1}\right)$, and the trachea was intubated. Ventilation was controlled with a Harvard pump (Harvard Apparatus Co., Inc., S. Natick, Mass.) set to maintain arterial carbon dioxide tension $\left(\mathrm{PaCO}_{2}\right)$ at 35 to $40 \mathrm{~mm} \mathrm{Hg}$ and an arterial oxygen tension $\left(\mathrm{PaO}_{2}\right)$ greater than $150 \mathrm{~mm} \mathrm{Hg}$. Anesthesia was maintained with isoflurane $0.5 \%$ to $1.5 \%$ inspired and fentanyl and midazolam (bolus: $250 \mu \mathrm{g} \cdot \mathrm{kg}^{-1}$ fentanyl and $350 \mu \mathrm{g}$. $\mathrm{kg}^{-1}$ midazolam, followed by infusion: fentanyl $3.0 \mu \mathrm{g}$. $\mathrm{kg}^{-1} \cdot \mathrm{min}^{-1}$ and midazolam $\left.9.6 \mu \mathrm{g} \cdot \mathrm{kg}^{-1} \cdot \mathrm{min}^{-1}\right)$. Muscle relaxation was maintained by continuous infusion of pancuronium $\left(0.8 \mu \mathrm{g} \cdot \mathrm{kg}^{-1} \cdot \mathrm{min}^{-1}\right)$.

A cannula was surgically inserted into a femoral artery for mean arterial blood pressure measurements and blood sampling. Body temperature was measured with a nasopharyngeal thermistor.

For CPB, a left-sided thoracotomy was performed. Venous drainage to the extracorporeal circuit was by a $36 \mathrm{~F}$ cannula placed in the right atrium via the right atrial appendage. The blood was circulated by centrifugal pump through a combined heat exchanger-oxygenator (Bentley Univox, Irvine, Calif.) and returned via a cannula ( $4.4 \mathrm{~mm}$ inner diameter) into the root of the aorta. Before aortic cannulation, intravenous heparin was given to maintain an activated coagulation time greater than 600 seconds. The bypass machine was primed with blood (approximately $750 \mathrm{ml}$ ) from a donor dog and with saline solution (about $250 \mathrm{ml}$ ). Mean arterial pressure was maintained between 55 and $70 \mathrm{~mm} \mathrm{Hg}$ throughout the period of bypass by altering bypass pump flow. No vasoconstrictors or vasodilators were used. Arterial hemoglobin concentration, blood temperature, and blood gas data were continuously monitored by in-line detectors (CDI 100 and CDI 400, Cardiovascular Devices, Inc., Tustin, Calif.). Pump flow was measured with an in-line ultrasonic blood flowmeter (Sarns/3M, Ann Arbor, Mich.).

After establishment of CPB, control measurements and blood samples were obtained after the target nasopharyngeal temperature of $37.5^{\circ} \mathrm{C}$ to $38.5^{\circ} \mathrm{C}$ (low normal dog temperature) was achieved. Arterial blood was drawn from the femoral line and mixed venous blood was drawn from the venous return line just proximal to the CPB reservoir. Arterial and venous oxygen and carbon dioxide partial pressures $\left(\mathrm{PO}_{2}, \mathrm{PCO}_{2}\right)$ and $\mathrm{pH}$ were measured with an IL $1306 \mathrm{pH}$ and blood gas analyzer (Instrumentation Laboratories, Inc., Lexington, Mass.) with the electrodes maintained at $37^{\circ} \mathrm{C}$. Hemoglobin concentration and oxygen saturation were measured by an IL 482 Co-Oximeter (Instrumentation Laboratories) with its coefficient setting selected for canine blood. Venous lactate levels were measured with a YSI model 23A analyzer (Yellow Springs Instrumentation, Yellow Springs, Ohio).

Oxygen consumption, oxygen delivery, oxygen extraction ratio, and total peripheral resistance were calculated by means of standard equations.

Oxygen consumption $\left(\dot{\mathrm{V}}_{2}\right)$ :

$$
\dot{\mathrm{V}}_{2}=\frac{\left(\text { Pump flow } \cdot \mathrm{AVDO}_{2}\right)}{\mathrm{BSA}} \mathrm{ml} \mathrm{O}_{2} \cdot \mathrm{min}^{-1} \cdot \mathrm{m}^{-2}
$$

where $B S A=$ body surface area.

Arteriovenous oxygen content difference $\left(\mathrm{AVDO}_{2}\right)$ :

$$
\mathrm{AVDO}_{2}=\left(\mathrm{CaO}_{2}-\mathrm{CVO}_{2}\right) \mathrm{ml} \cdot \mathrm{dl}^{-1}
$$

Arterial or venous oxygen content $\left(\mathrm{CxO}_{2}\right)$ :

$$
\mathrm{CxO}_{2}=1.34 \mathrm{Hb}\left(\mathrm{SxO}_{2}\right)+0.003\left(\mathrm{PxO}_{2}\right)
$$

where $\mathrm{Hb}=$ hemoglobin concentration; $\mathrm{SVO}_{2}=$ oxygen saturation; $\mathrm{PxO}_{2}=$ partial pressure of oxygen; and $x=$ arterial or venous. 
Oxygen delivery $\left(\mathrm{Do}_{2}\right)$ :

$$
\mathrm{Do}_{2}=\frac{\text { Pump flow } \cdot \mathrm{CaO}_{2}}{\mathrm{BSA}} \mathrm{ml} \mathrm{O} \cdot \mathrm{min}^{-1} \cdot \mathrm{m}^{-2}
$$

Oxygen extraction ratio (OER):

$$
\mathrm{OER}=\frac{\dot{\mathrm{V}}_{2}}{\mathrm{DO}_{2}}
$$

Total peripheral resistance (TPR):

$$
\mathrm{TPR}=\frac{(\mathrm{MAP}-\mathrm{CVP}) \cdot 80}{\text { Pump flow }} \text { dynes } \cdot \mathrm{sec} \cdot \mathrm{cm}^{-5}
$$

where $M A P=$ mean arterial pressure and $C V P=$ central venous pressure.

An oversized $(36 \mathrm{~F}$ ) venous cannula (for a $20 \mathrm{~kg}$ dog) was placed in the right atrium to ensure complete right heart drainage such that the central venous pressure could be assumed to be negligible.

Hemodilution was achieved by removing blood from the $\mathrm{CPB}$ circuit and replacing it with $6 \%$ dextran 70 . After each reduction in hematocrit value, a period of hemodynamic stabilization of at least 15 minutes was allowed before blood samples were withdrawn and measurements recorded. Mixed venous oxygen saturation was also monitored for stability before measurement recording and blood sampling.

Statistical analysis. All physiologic and metabolic data collected at the five levels of hemodilution during CPB were analyzed by means of repeated-measures analysis of variance. Differences between the five periods (with period 1 designated as control) were determined by the Student-Newman-Keuls test when necessary. All values are expressed as mean \pm standard deviation. Regression curves for oxygen delivery, oxygen consumption, and total peripheral resistance were generated from the 45 individual data points for each variable at each measured hematocrit value. The data were fit to a logarithmic curve by means of the formula $y=a+b(\ln x)$. The figures present these curves, as well as mean values and standard deviations for each variable.

\section{Results}

As hematocrit value was reduced from $40 \%$ to $9 \%$, systemic physiologic variables remained stable (Table I). Throughout CPB, temperature, mean arterial pressure, $\mathrm{PaO}_{2}, \mathrm{PaCO}_{2}$, and $\mathrm{pH}$ remained unchanged. The $\mathrm{pH}$ tended to decrease in the final hemodilution step, but this decrease did not reach statistical significance (Table I).

Progressive hemodilution resulted in a progressive reduction in total peripheral resistance (Fig. 1, Table II). However, mean arterial pressure was maintained at approximately $62 \mathrm{~mm} \mathrm{Hg}$ throughout the study by increases in pump flow. A $50 \%$ increase in pump flow was required to maintain mean arterial pressure as hematocrit value was reduced from $39 \%$ to $18 \%$ (Table II). The oxygen delivery at a hemat-

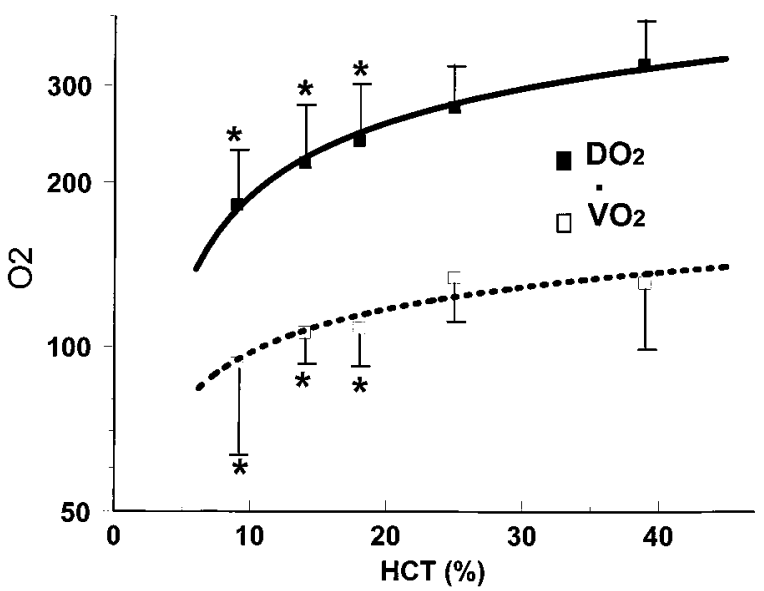

Fig. 2. Whole body oxygen consumption $\left(\dot{V} \mathrm{O}_{2}\right)(\square)$ in $\mathrm{ml} \cdot \mathrm{min}^{-1} \cdot \mathrm{m}^{-2}$ and oxygen delivery $\left(\mathrm{Do}_{2}\right)(\boldsymbol{\square})$ in $\mathrm{ml} \cdot$ $\min ^{-1} \cdot \mathrm{m}^{-2}$ versus hematocrit $(H c t)$ during the five CPB study periods. Values are mean \pm standard deviation $(n=$ 9). Each regression curve was generated from 45 individual values of oxygen consumption and oxygen delivery at individual hematocrit levels.

ocrit value of $23 \%$ was $274 \mathrm{ml} \cdot \mathrm{min}^{-1} \cdot \mathrm{m}^{-2}(11.5$ $\left.\mathrm{ml} \cdot \mathrm{kg}^{-1} \cdot \mathrm{min}^{-1}\right)$ and did not differ from the oxygen delivery at a hematocrit value of $39 \%$. Only when hematocrit concentration was reduced to $18 \% \pm 2 \%$ was there a significant decrease in systemic oxygen delivery to $238 \mathrm{ml} \cdot \mathrm{min}^{-1} \cdot \mathrm{m}^{-2}\left(10 \mathrm{ml} \cdot \mathrm{kg}^{-1} \cdot \mathrm{min}^{-1}\right)$. Similarly, systemic oxygen consumption was stable between hematocrit values of $39 \%$ and $25 \%$ and showed a significant reduction at a hematocrit value of $18 \%$ and below (Table II, Fig. 2).

During normothermic CPB with a hematocrit value of $39 \%$, the venous oxygen saturation was $57 \%$. This tended to decrease with progressive hemodilution and was $50 \%$ or less when the hematocrit value was $18 \%$ or below. The oxygen extraction ratio also tended to rise throughout $\mathrm{CPB}$ and increased from $41 \%$ to approximately $55 \%$ as hemoglobin concentration was progressively reduced. Changes in venous lactate parallel changes in the oxygen extraction ratio (Table II).

\section{Discussion}

The beneficial effects of hemodilution during CPB are well recognized. CPB hemodilution reduces the demand for blood therapy and may reduce the incidence of transfusion-related complications. Under both $\mathrm{CPB}$ and non-CPB conditions, hemodilution increases blood flow in a variety of organ beds. $^{2,4,11,12}$ This effect may be particularly advan- 
Table I. Systemic physiologic variables with progressive hemodilution during normothermic CPB

\begin{tabular}{ccccccc}
\hline CPB period & $\begin{array}{c}\mathrm{Hct} \\
(\%)\end{array}$ & $\begin{array}{c}\mathrm{Temp} \\
\left({ }^{\circ} \mathrm{C}\right)\end{array}$ & $\begin{array}{c}\mathrm{MAP} \\
(\mathrm{mm} \mathrm{Hg})\end{array}$ & $\begin{array}{c}\mathrm{PaO}_{2} \\
(\mathrm{~mm} \mathrm{Hg})\end{array}$ & $\begin{array}{c}\mathrm{PaCO}_{2} \\
(\mathrm{~mm} \mathrm{Hg})\end{array}$ & $\begin{array}{c}\mathrm{HH}^{2} \\
2\end{array}$ \\
\hline 1 & $39 \pm 6$ & $38 \pm 0.9$ & $62 \pm 10$ & $253 \pm 93$ & $36 \pm 3$ & $7.35 \pm 0.06$ \\
3 & $25 \pm 2$ & $38.5 \pm 0.8$ & $62 \pm 4$ & $302 \pm 105$ & $37 \pm 4$ & $7.33 \pm 0.07$ \\
4 & $18 \pm 2^{*}$ & $38.0 \pm 0.3$ & $62 \pm 3$ & $260 \pm 83$ & $34 \pm 3$ & $7.35 \pm 0.04$ \\
5 & $14 \pm 1^{*}$ & $38.1 \pm 0.5$ & $62 \pm 5$ & $279 \pm 93$ & $37 \pm 3$ & $7.33 \pm 0.06$ \\
& $9 \pm 1^{*}$ & $38.1 \pm 0.5$ & $62 \pm 5$ & $290 \pm 63$ & $37 \pm 6$ & $7.31 \pm 0.04$ \\
\hline
\end{tabular}

Data are mean \pm standard deviation $(n=9)$. CPB, Cardiopulmonary bypass; $H c t$, hematocrit value; Temp, temperature; $M A P$, mean arterial pressure. ${ }^{*} p<0.05$ versus $\mathrm{CPB}$ period 1 .

tageous during hypothermic $\mathrm{CPB}$ when the reduction in blood viscosity with hemodilution ${ }^{13}$ counteracts the effect of cold-induced vasoconstriction and the increased blood viscosity associated with reduced body temperature. ${ }^{14}$

As a result of the reports of the Toronto investigators in $1991,{ }^{8,9}$ there has been a shift toward normothermic CPB across North America. With this shift, there was a tendency at our institution and others to require higher hematocrit values during $\mathrm{CPB}$, but this practice change was not based on systematic physiologic data on oxygen balance. Generally, guidelines as to "temperature appropriate hematocrit" would be of practical relevance but are largely lacking. Even for institutions not practicing warm $\mathrm{CPB}$, patients approximate normothermia in the initial and late phases of CPB. During these periods hematocrit may be of particular relevance.

Typically, hemodilution during normothermic $\mathrm{CPB}$ results in hypotension, and it is common practice to support mean arterial pressure with a vasoconstrictor. In this investigation, we chose to increase pump flow to maintain mean arterial pressure rather than use an alpha agonist, for two reasons. First, supporting arterial pressure with pump flow allowed us to characterize the relationship between hematocrit value and peripheral resistance during CPB. Second, under non-CPB conditions the response to hemodilution is an increase in cardiac output rather than systemic vasoconstriction; as such, an increase in pump flow more closely mimics the physiologic response in the intact circulation. During CPB at equivalent blood pressures, tissue perfusion should be better maintained with increases in flow than with addition of a vasoconstrictor. $^{15}$

Our study was designed to identify the minimal hematocrit level that supports whole body oxygen consumption during normothermic CPB. We found that systemic oxygen consumption is maintained at a hematocrit value of $25 \%$ but was reduced at $18 \%$.
Interestingly, this range was higher than the reported "critical" hematocrit level of approximately $10 \%$ under non-CPB conditions. ${ }^{5}$ However, we found that during warm $\mathrm{CPB}$, the critical oxygen delivery was approximately $10 \mathrm{ml} \cdot 100 \mathrm{gm}^{-1} \cdot \mathrm{min}^{-1}$. This is essentially the same as the value reported by Cain $^{5}\left(9.8 \mathrm{ml} \cdot 100 \mathrm{gm}^{-1} \cdot \mathrm{min}^{-1}\right)$ under non-CPB conditions. From this observation, two conclusions may be drawn: First, CPB per se does not alter the critical level of oxygen transport; second, and more important, a higher hematocrit value may be indicated under CPB than non-CPB conditions. In the intact dog, the same critical oxygen delivery is obtained at a much lower hematocrit value $(10 \%)$ because the intact animal is better able to increase its cardiac output than we are able to increase CPB pump flow. In our study, at a hematocrit value of $18 \%$, the mean pump flow was 2.9 (or $122 \mathrm{ml}$. $\left.\mathrm{kg}^{-1} \cdot \min ^{-1}\right)$. Cain's dogs reached the same critical oxygen delivery when the hematocrit value was approximately $10 \%$ because the cardiac output was $300 \mathrm{ml} \cdot \mathrm{kg}^{-1} \cdot \mathrm{min}^{-1}$, a cardiac index of about 6 $\mathrm{L} \cdot \mathrm{min}^{-1} \cdot \mathrm{m}^{-2}$. Because there are technical limitations to increasing CPB flows much above 2.6 or 2.8 $\mathrm{L} \cdot \mathrm{min}^{-1} \cdot \mathrm{m}^{-2}$, oxygen delivery may be compromised by the limited "cardiac output" response to reduced hematocrit during clinical CPB.

We also found that the critical hematocrit value for the body during warm CPB is higher than that reported for the brain under the same conditions. ${ }^{16}$ In a different study, we determined that cerebral oxygen demand in dogs is met with a hematocrit value as low as $15 \%$. We anticipated that the body would be more tolerant of hemodilution than the brain because of its lower oxygen demand per unit weight and higher oxidative reserve. However, the brain is very effective in increasing its flow at low hematocrit values such that cerebral perfusion is maintained by shunting flow from other organ beds. ${ }^{17,18}$ In this way, systemic oxygenation is compromised before cerebral oxygenation. 
Table II. Effect of hemodilution on total peripheral resistance, pump flow, and whole body oxygen balance during normothermic $C P B$

\begin{tabular}{cccccccc}
\hline CPB period & $\begin{array}{c}\mathrm{TPR} \\
\left(\text { dynes } \cdot \mathrm{s} \cdot \mathrm{cm}^{-5}\right)\end{array}$ & $\begin{array}{c}\text { Pump flow } \\
\left(\mathrm{L} \cdot \mathrm{min}^{-1} \cdot \mathrm{m}^{-2}\right)\end{array}$ & $\begin{array}{c}\mathrm{Do}_{2} \\
\left(\mathrm{ml} \cdot \mathrm{min}^{-1} \cdot \mathrm{m}^{-2}\right)\end{array}$ & $\begin{array}{c}\dot{\mathrm{VO}} \mathrm{O}_{2} \\
\left(\mathrm{ml} \cdot \mathrm{min}^{-1} \cdot \mathrm{m}^{-2}\right)\end{array}$ & $\begin{array}{c}\mathrm{OER}^{2} \\
(\%)\end{array}$ & $\begin{array}{c}\mathrm{SVO}_{2} \\
(\%)\end{array}$ & $\begin{array}{c}\text { Lactate } \\
\left(\mathrm{mmol} \cdot \mathrm{ml}^{-1}\right)\end{array}$ \\
\hline 1 & $3390 \pm 900$ & $1.9 \pm 0.5$ & $327 \pm 69$ & $131 \pm 31$ & $41 \pm 7$ & $57 \pm 7$ & $3.3 \pm 0.8$ \\
2 & $2760 \pm 640^{*}$ & $2.3 \pm 0.4$ & $274 \pm 54$ & $134 \pm 21$ & $50 \pm 7$ & $52 \pm 5$ & $3.1 \pm 0.8$ \\
3 & $2370 \pm 840^{*}$ & $2.9 \pm 0.9^{*}$ & $238 \pm 69^{*}$ & $108 \pm 17^{*}$ & $49 \pm 16$ & $49 \pm 12$ & $3.4 \pm 1.5$ \\
4 & $1990 \pm 570^{*}$ & $3.4 \pm 0.9^{*}$ & $217 \pm 61^{*}$ & $106 \pm 13^{*}$ & $52 \pm 13$ & $50 \pm 13$ & $3.9 \pm 1.9$ \\
5 & $1740 \pm 570^{*}$ & $3.8 \pm 1.1^{*}$ & $182 \pm 48^{*}$ & $93 \pm 30^{*}$ & $54 \pm 18$ & $47 \pm 13$ & $4.6 \pm 2.1^{*}$ \\
\hline
\end{tabular}

Data are mean \pm standard deviation $(n=9)$. $C P B$, Cardiopulmonary bypass; $T P R$, total peripheral resistance; $\mathrm{Do}_{2}$, total oxygen delivery; $\dot{V}_{2}$, whole body oxygen consumption; $\mathrm{OER}$, oxygen extraction ratio; $\mathrm{SVO}_{2}$, mixed venous oxygen saturation.

${ }^{*} p<0.05$ versus CPB period 1 .

Our study might be criticized for several reasons. First, a pre-CPB systemic oxygen consumption was not reported. However, our pre-hemodilution value is consistent with previously reported values in dogs under non-CPB conditions. In the foundation work by $\operatorname{Starr}^{19}$ in 1959 , the same value was documented before CPB. Our systemic oxygen consumption during $\mathrm{CPB}$ period 1 also falls between the values reported by Gutierrez and associates ${ }^{20}$ and Cain ${ }^{5}$ under non-CPB conditions. Therefore the systemic oxygen consumption of the initial CPB period can be expected to closely approximate the animal's oxygen consumption before CPB.

Second, the oxygen extraction ratio was higher $(41 \%)$ and oxygen saturation lower $(57 \%)$ than might be expected during CPB with a whole blood prime. Although in the normal range, the values during the initial period of CPB (hematocrit value $39 \%$ ) suggest that either the mean arterial pressure or pump flow may have been somewhat low relative to systemic oxygen consumption. We targeted a mean arterial pressure of $60 \mathrm{~mm} \mathrm{Hg}$ to reflect clinical perfusion practice. However, a dog, like the adult patient with cardiac disease, typically has a mean arterial pressure closer to $80 \mathrm{~mm} \mathrm{Hg}$ under non-CPB conditions. As such, higher mean arterial pressures or pump flows may be appropriate under normothermic conditions, particularly as hematocrit is reduced.

Most studies of this type also face a methodologic limitation. As in our study, the determination of systemic oxygen consumption and oxygen delivery may be linked mathematically as well as physiologically. This is of particular importance when correlations are performed, and this potential problem can be minimized by determination of linked or coupled variables using independent techniques. ${ }^{21}$ Our laboratory, like most others reporting similar studies, is unable to provide calorimetric studies or direct measurements of systemic oxygen consumption and so is compelled to rely on the Fick method. However, we do realize the inherent limitation of the technique.

Finally, we provide an assessment of systemic oxygen balance at five levels of hematocrit but cannot clearly identify the single lowest acceptable hematocrit level for warm CPB. Our data indicate that a hematocrit value of $18 \%$ is too low with conventional CPB but that $25 \%$ is adequate. Ideally, oxygen balance at a hematocrit level between these values would have been determined. However, on the basis of non-CPB studies, we expected that the "critical" hematocrit value would be lower than $18 \%$ and we were surprised by the finding that critical oxygen delivery is reached at a higher hematocrit value under $\mathrm{CPB}$ than non-CPB conditions. This finding suggests that the minimal acceptable hematocrit value is not a fixed number but will vary within a range, in large part a function of the CPB flow. At a fixed flow, a critical hematocrit value might be more rigidly defined, but if flow adjustments are made, a lower (or higher) hematocrit level will be critical. Nonetheless, until certain practical limitations in CPB circuitry are overcome, the critical hematocrit value closely approximates $18 \%$ to $20 \%$ at normothermia with conventional flow rates.

In conclusion, we found that $\mathrm{CPB}$ does not appear to alter whole body consumption or critical oxygen delivery values. We found that whole body oxygen consumption is not maintained when the hematocrit value is reduced to $18 \%$ during normothermic CPB. The reason is probably that the increases in pump flow that are practical during CPB do not approximate what would be seen under non-CPB conditions at equivalent hematocrit levels. It is important to emphasize that we do not define what is a "safe" hematocrit value under normothermic conditions; many physiologic aberrations can be tolerated for 
brief periods of time, but it must also be kept in mind that normal dogs will tolerate a lower hematocrit value than today's older adult patient undergoing cardiac surgery. Nonetheless, we hope these findings begin to provide a better physiologic framework for our clinical practice.

\section{REFERENCES}

1. Hall TS. The pathophysiology of cardiopulmonary bypass: the risks and benefits of hemodilution. Chest 1995;107:1125-33.

2. Messmer K. Hemodilution. Surg Clin North Am 1975;55:65978.

3. Fan FC, Chen RY, Schuessler GB, Chien S. Effects of hematocrit variations on regional hemodynamics and oxygen transport in the dog. Am J Physiol 1980;238:H545-622.

4. Chapler CK, Cain SM. The physiologic reserve in oxygen carrying capacity: studies in experimental hemodilution. Can J Physiol Pharmacol 1986:4:7-12.

5. Cain SM. Oxygen delivery and uptake in dogs during anemic and hypoxic hypoxia. J Appl Physiol 1977;42:228-34.

6. Goodnough LT, Johnston MFM, Toy PCY. The variability of transfusion in practice in coronary artery bypass surgery. Transfusion Medicine Academic Award Group. JAMA 1991; 265:86-90.

7. Goodnough LT, Despotis GJ, Hogue CW Jr, Ferguson TB Jr. On the need for improved transfusion indicators in cardiac surgery. Ann Thorac Surg 1995;60:473-80.

8. Lichtenstein SV, Ashe KA, El Dalati H, Cusimano RJ, Panos A, Slutsky AS. Warm heart surgery. J Thorac Cardiovasc Surg 1991;101:269-74.

9. Christakis GT, Koch JP, Deemar KA, Fremes SE, Sinclair L, Chen E, et al. A randomized study of the systemic effects of warm heart surgery. Ann Thorac Surg 1992;54:449-59.

10. Lehot J-J, Villard J, Piriz H, Philbin DM, Carry P-Y, Gauquelin G, et al. Hemodynamic and hormonal responses to hypothermic and normothermic cardiopulmonary bypass. J Cardiothorac Vasc Anesth 1992;6:132-9.
11. Cook DJ, Oliver WC Jr, Orszulak TA, Daly RC, Bryce RD. Cardiopulmonary bypass temperature, hematocrit, and cerebral oxygen delivery in humans. Ann Thorac Surg 1995;60: 1671-7.

12. Utley JR, Stephens DB, Wachtel C, Cain RB, Collins JC, Spaw EA, et al. Effect of albumin and mannitol on organ blood flow, oxygen delivery, water content, and renal function during hypothermic hemodilution cardiopulmonary bypass. Ann Thorac Surg 1982;33:250-7.

13. Gordon RJ, Ravin M, Rawitscher RE, Daicoff GR. Changes in arterial pressure, viscosity, and resistance during cardiopulmonary bypass. J Thorac Cardiovasc Surg 1975;69:552-61.

14. Rand PW, Lacombe E, Hunt HE, Austin WH. Viscosity of normal human blood under normothermic and hypothermic conditions. J Appl Physiol 1964;19:117-22.

15. O'Dwyer C, Woodson LC, Conroy BP, Lin CY, Deyo DJ, Uchida $\mathrm{T}$, et al. Regional perfusion abnormalities with phenylephrine during normothermic bypass. Ann Thorac Surg 1997;63:728-35.

16. Cook DJ, Orszulak TA, Daly RC, MacVeigh I. Minimum hematocrit for normothermic cardiopulmonary bypass in dogs. Circulation 1997;96(Suppl):II200-4.

17. Fox LS, Blackstone EH, Kirklin JW, Bishop SP, Bergdahl LA, Bradley EL, et al. Relationship of brain blood flow and oxygen consumption to perfusion flow rate during profoundly hypothermic cardiopulmonary bypass: an experimental study. J Thorac Cardiovasc Surg 1984;87:658-64.

18. Cook DJ, Orszulak TA, Daly RC. The effects of pulsatile cardiopulmonary bypass on cerebral and renal blood flow in dogs. J Cardiothorac Vasc Anesth 1997;11:420-7.

19. Starr A. Oxygen consumption during cardiopulmonary bypass. J Thorac Cardiovasc Surg 1959;58:46-56.

20. Gutierrez G, Warley AR, Dantzker DR. Oxygen delivery and utilization in hypothermic dogs. J Appl Physiol 1986;60: 751-7.

21. Archie JPJ. Mathematic coupling of data: a common source of error. Ann Surg 1981;193:296-303. 